\title{
GENERALIZED WEIGHTED COMPOSITION OPERATORS ON WEIGHTED BERGMAN SPACES, II
}

\author{
XIANGLing ZHU
}

Abstract. The boundedness, compactness, essential norm, Hilbert-Schmidt class and order boundedness of generalized weighted composition operators on weighted Bergman spaces are investigated in this paper.

Mathematics subject classification (2010): 30H30, 47B38.

Keywords and phrases: Generalized weighted composition operator, Hilbert-Schmidt, weighted Bergman space.

\section{REFERENCES}

[1] R. Aulas Kari, D. Stegenga And J. Xiao, Some subclasses of BMOA and their characterizations in terms of Carleson measures, Rocky Mountain J. Math. 26 (1996), 485-506.

[2] C. Cowen And B. MacCluer, Composition Operators on Spaces of Analytic Functions, CRC Press, Boca Raton, FL, 1995.

[3] Z. ČUČKOVIĆ AND R. ZHAO, Weighted composition operators on the Bergman space, J. London Math. Soc. 70 (2004), 499-511.

[4] R. Hibschweiler And N. Portnoy, Composition followed by differentiation between Bergman and Hardy spaces, Rocky Mountain J. Math. 35 (2005), 843-855.

[5] Q. HU AND X. ZHU, A new characterization of differences of generalized weighted composition operators from the Bloch space into weighted-type spaces, Math. Inequal. Appl. 21(1)(2018), 63-76.

[6] H. LI AND X. FU, A new characterization of generalized weighted composition operators from the Bloch space into the Zygmund space, J. Funct. Spaces Appl. Volume 2013, Article ID 925901, 12 pages.

[7] S. Li AND S. STEVIĆ, Composition followed by differentiation from mixed-norm spaces to $\alpha$-Bloch spaces, Sb. Math. 199 (12) (2008), 1847-1857.

[8] S. Li And S. Stević, Composition followed by differentiation between $H^{\infty}$ and $\alpha$-Bloch spaces, Houston J. Math. 35 (2009), 327-340.

[9] S. Li AND S. STEVIĆ, Products of composition and differentiation operators from Zygmund spaces to Bloch spaces and Bers spaces, Appl. Math. Comput. 217 (2010), 3144-3154.

[10] S. Li AND S. STEVIĆ, Generalized weighted composition operators from $\alpha$-Bloch spaces into weighted-type spaces, J. Ineq. Appl. Vol. 2015, Article No. 265, (2015), 12 pages.

[11] S. Li AND S. STEvić, Weighted differentiation composition operators from the logarithmic Bloch space to the weighted-type space, An. Stiint. Univ. "Ovidius" Constanta Ser. Mat. 24 (3)(2016), 223240.

[12] Y. LIANG AND Z. ZHOU, Essential norm of the product of differentiation and composition operators between Bloch-type space, Arch. Math. 100 (2013), 347-360.

[13] X. LiU And S. LI, Differences of generalized weighted composition operators from the Bloch space into Bers-type spaces, Filomat, 31 (6)(2018), 1671-1680.

[14] D. LueCKING, Forward and reverse Carleson inequalities for functions in Bergman spaces and their derivatives, Amer. J. Math. 107 (1985), 85-111.

[15] J. RÄTTY Ä, The essential norm of a composition operator mapping into the $\mathscr{Q}_{s}$-space, J. Math. Anal. Appl. 333 (2007), 787-797. 
[16] B. Sehba And S. STević, On some product-type operators from Hardy-Orlicz and Bergman-Orlicz spaces to weighted-type spaces, Appl. Math. Comput. 233 (2014), 565-581.

[17] S. STEVIĆ, Integral-type operators from a mixed norm space to a Bloch-type space on the unit ball, Siberian Math. J. 50 (6) (2009), 1098-1105.

[18] S. STEVIĆ, Norm and essential norm of composition followed by differentiation from $\alpha$-Bloch spaces to $H_{\mu}^{\infty}$, Appl. Math.Comput. 207 (2009), 225-229.

[19] S. STEviĆ, Products of composition and differentiation operators on the weighted Bergman space, Bull. Belg. Math. Soc. Simon Stevin 16 (2009), 623-635.

[20] S. STEVIĆ, Weighted differentiation composition operators from mixed-norm spaces to weighted-type spaces, Appl. Math. Comput. 211 (2009), 222-233.

[21] S. STEvić, Composition followed by differentiation from $H^{\infty}$ and Bloch spaces to $n$th weighted-type spaces on the unit disk, Appl. Math. Comput. 216 (2010), 3450-3458.

[22] S. STEvić, Weighted differentiation composition operators from $H^{\infty}$ and Bloch spaces to $n$th weigthed-type spaces on the unit disk, Appl. Math. Comput. 216 (2010), 3634-3641.

[23] S. STEVIĆ, Weighted differentiation composition operators from mixed-norm spaces to the nth weighted-type space on the unit disk, Abstr. Appl. Anal. Vol. 2010, Article ID 246287, (2010), 15 pages.

[24] S. STEVIĆ, Weighted iterated radial composition operators between some spaces of holomorphic functions on the unit ball, Abstr. Appl. Anal. Vol. 2010, Article ID 801264, (2010), 14 pages.

[25] S. STEVIĆ, Characterizations of composition followed by differentiation between Bloch-type spaces, Appl. Math. Comput. 218 (2011), 4312-4316.

[26] S. STEVIĆ, Weighted iterated radial operators between different weighted Bergman spaces on the unit ball, Appl. Math. Comput. 218 (2012), 8288-8294.

[27] S. STEVIĆ AND A. K. Sharma, Iterated differentiation followed by composition from Bloch-type spaces to weighted BMOA spaces, Appl. Math. Comput. 218 (2011), 3574-3580.

[28] S. STEVIĆ, A. K. ShARMA AND A. Bhat, Essential norm of products of multiplication composition and differentiation operators on weighted Bergman spaces, Appl. Math. Comput. 218 (2011), 23862397.

[29] S. Stević, A. K. Sharma And A. Bhat, Products of multiplication composition and differentiation operators on weighted Bergman spaces, Appl. Math. Comput. 217 (2011), 8115-8125.

[30] S. UEKI, Order bounded weighted composition operators mapping into the Bergman space, Complex Anal. Oper. Theory 6 (2012), 549-560.

[31] Y. WU AND H. WULAN, Products of differentiation and composition operators on the Bloch space, Collet. Math. 63 (2012), 93-107.

[32] K. ZHu, Operator Theory in Function Spaces, Amer. Math. Soc., second edition, 2007.

[33] X. ZHU, Products of differentiation, composition and multiplication from Bergman type spaces to Bers type space, Integ. Tran. Spec. Funct. 18 (2007), 223-231.

[34] X. ZHU, Generalized weighted composition operators on weighted Bergman spaces, Numer. Funct. Anal. Opt. 30 (2009), 881-893.

[35] X. ZHU, Generalized weighted composition operators from Bloch spaces into Bers-type spaces, Filomat 26 (2012), 1163-1169.

[36] X. ZHU, Generalized weighted composition operators on Bloch-type spaces, J. Ineq. Appl. 2015 (2015), 59-68.

[37] X. ZHU, Essential norm of generalized weighted composition operators on Bloch-type spaces, Appl. Math. Comput. 274 (2016), 133-142. 